Scripting: an exploration of designing for participation over time with communities Peer-reviewed author version

HUYBRECHTS, Liesbeth; Hendriks, Niels; Yndigegn, Signe Louise \& Malmborg, Lone (2018) Scripting: an exploration of designing for participation over time with communities. In: CoDesign (Print), 14(1), p. 17-31.

DOI: $10.1080 / 15710882.2018 .1424205$

Handle: http://hdl.handle.net/1942/25514 


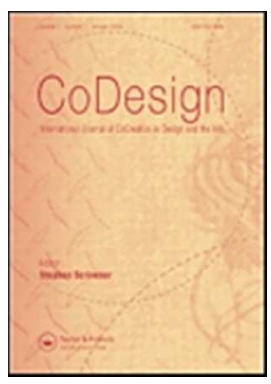

\section{Scripting: an exploration of designing for participation over time with communities}

\begin{tabular}{|r|l|}
\hline Journal: & CoDesign \\
\hline Manuscript ID & NCDN-2016-0081.R4 \\
\hline Manuscript Type: & Special Issue Paper \\
\hline Keywords: & participatory design, codesign, scripting \\
\hline & \\
& \\
\end{tabular}

SCHOLARONE $^{\text {IM }}$

Manuscripts 


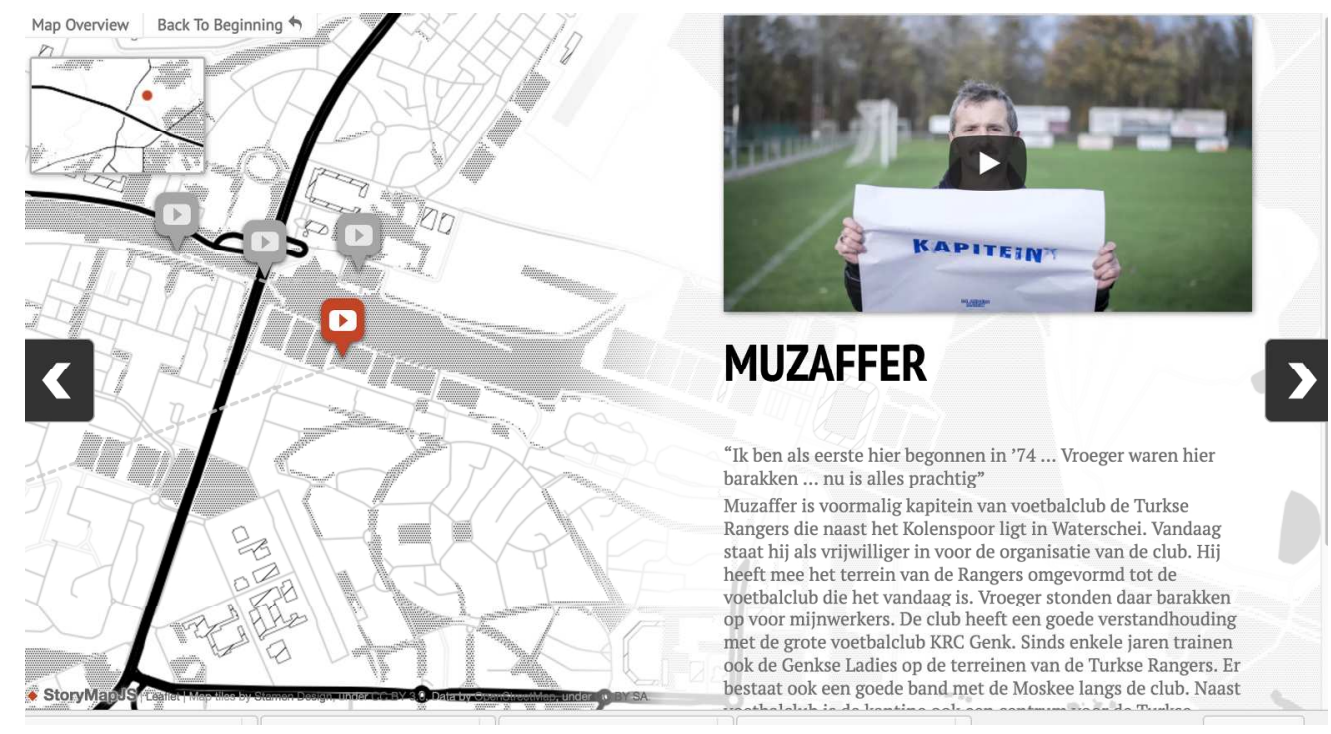

Figure 1. Web platform displaying personal scripts 


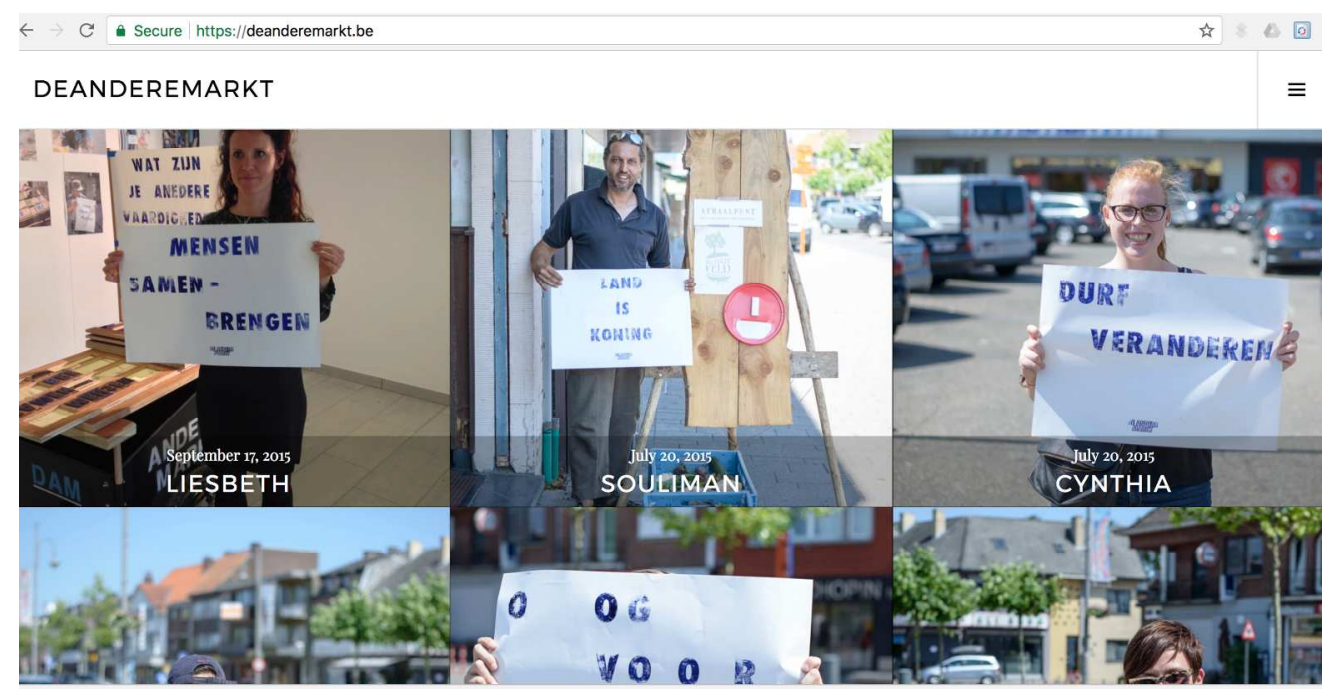

Figure 2. Web platform displaying the scripts in a spatial view 


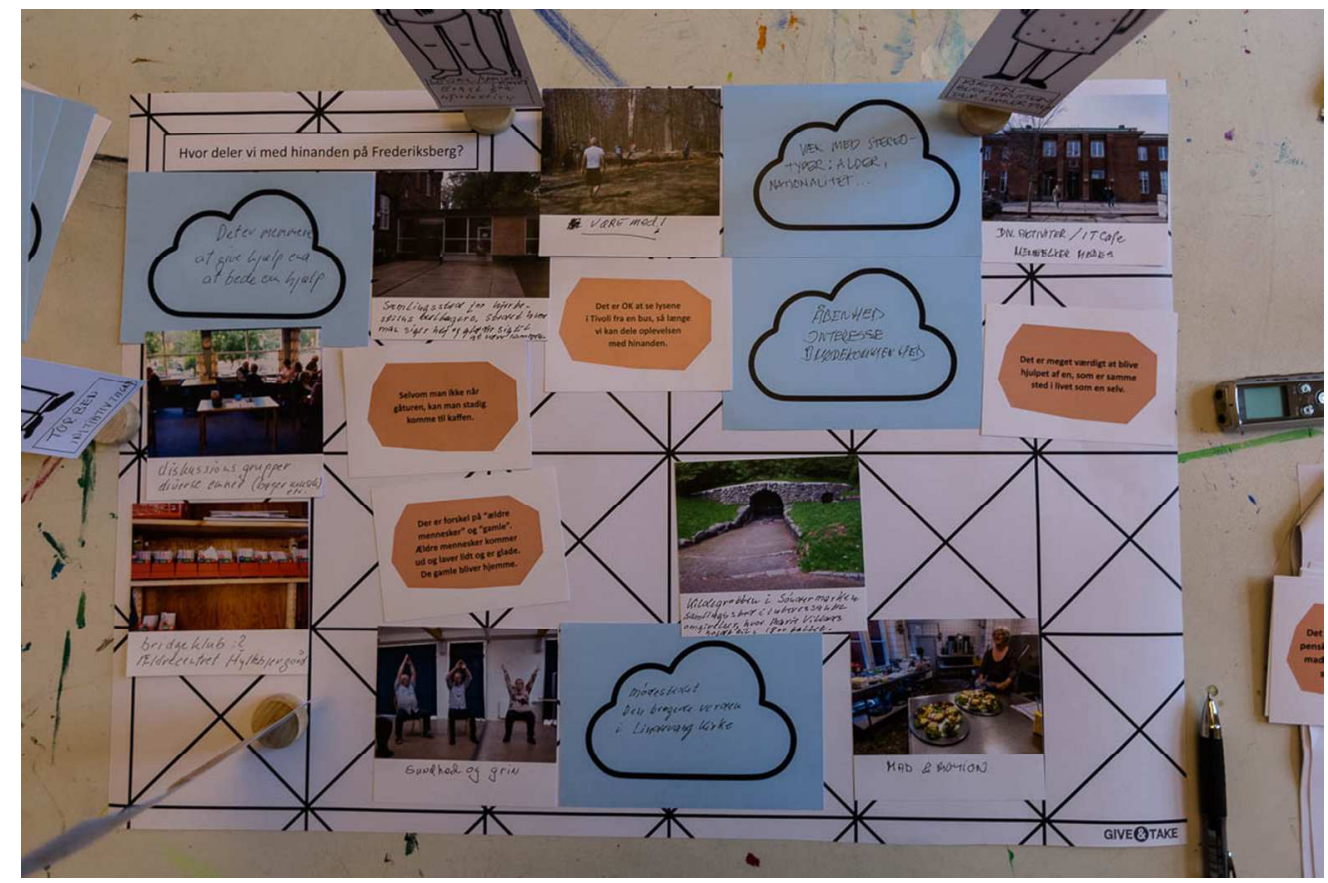

Figure 3. A game board-collage of personal scripts $435 \times 290 \mathrm{~mm}(70 \times 70$ DPI $)$ 


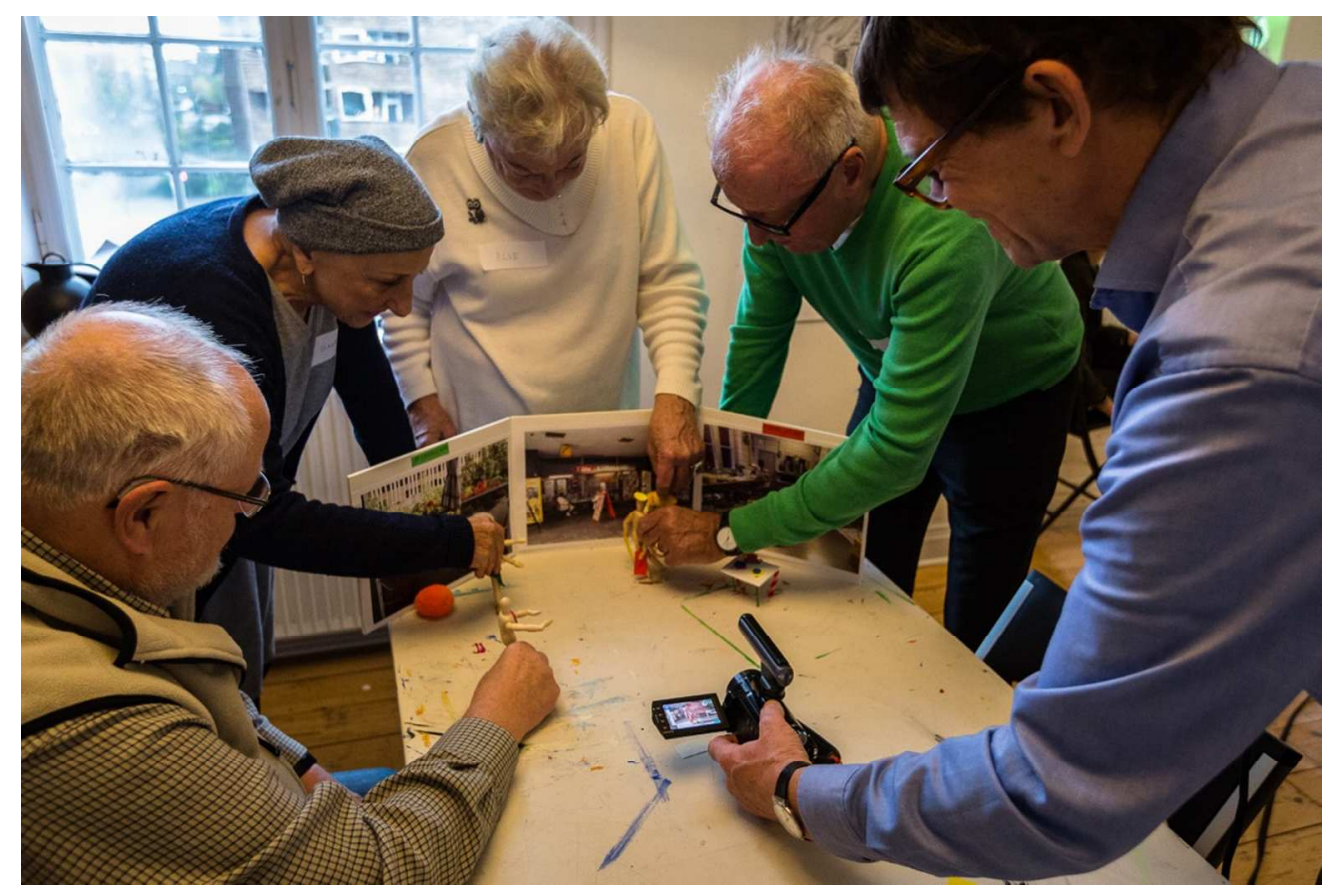

Figure 4. Enacting of community scripts that led to the 'onion model' of roles.

$$
451 \times 301 \mathrm{~mm}(72 \times 72 \mathrm{DPI})
$$




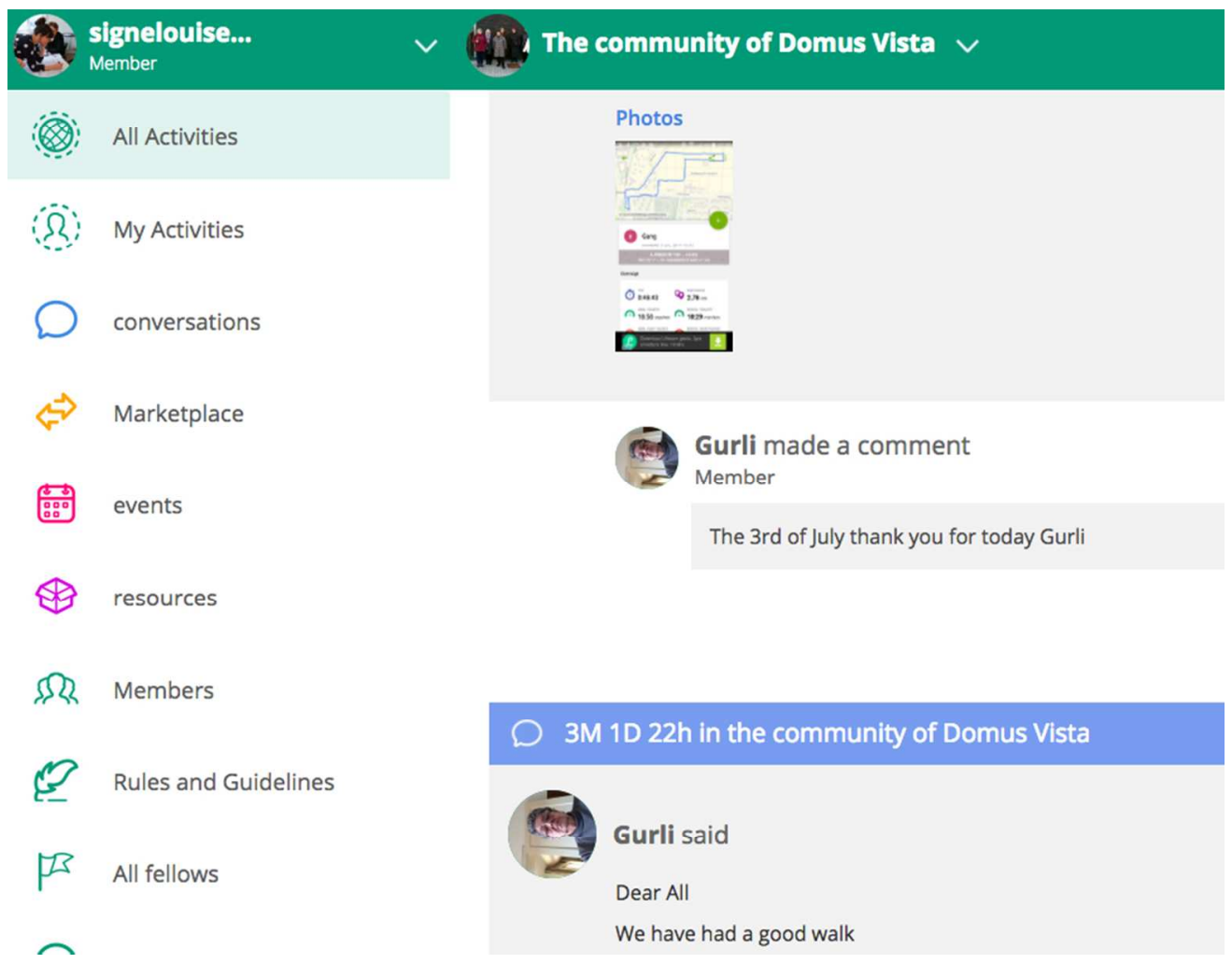

Figure 5. Screenshot from the walking community with latest walk (from Endomondo).

$340 \times 263 \mathrm{~mm}(72 \times 72$ DPI $)$ 


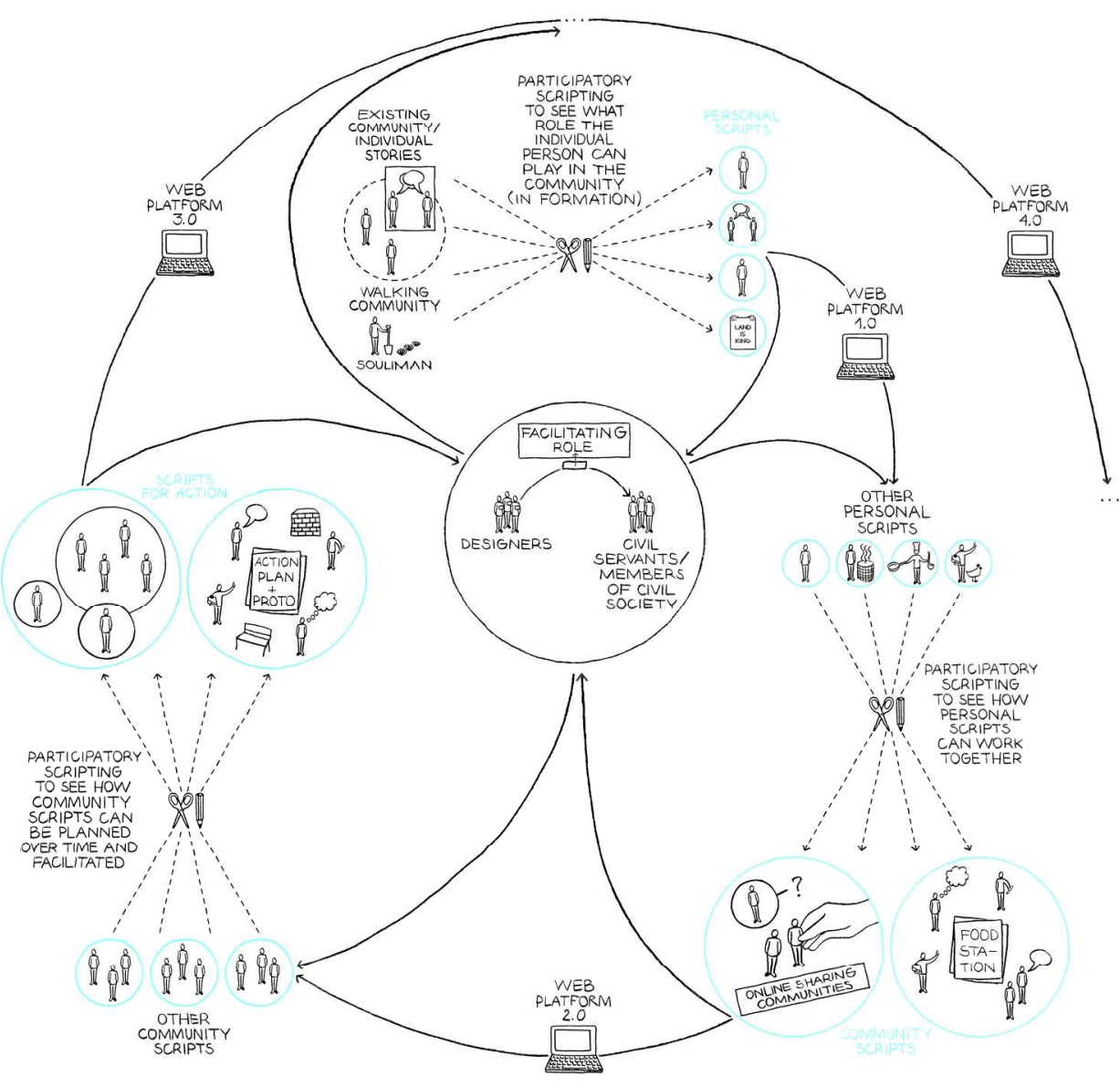

Figure 6. Overview of the scripting process

$209 \times 190 \mathrm{~mm}(300 \times 300$ DPI)

URL: http:/mc.manuscriptcentral.com/ncdn Email: j.mcdonnell@csm.arts.ac.uk 


\title{
Scripting: an exploration of designing for participation over time with communities
}

\author{
Liesbeth Huybrechts* \\ Arck, Hasselt University, Hasselt, Belgium \\ Niels Hendriks ${ }^{\circ}$ \\ LUCA - School of Arts, KU Leuven, Genk, Belgium
}

Signe Louise Yndigegn ${ }^{\wedge}$

Digital Design Department, IT University of Copenhagen, Denmark

Lone Malmborg^

Digital Design Department, IT University of Copenhagen, Denmark

*Campus Diepenbeek, Agoralaan Gebouw E, BE 3590 Diepenbeek Belgium, 003211

2921 01, liesbeth.huybrechts@uhasselt.be

${ }^{\circ} \mathrm{C}$-mine 5, 3600 Genk, Belgium, 0032893008 50, niels.hendriks@kuleuven.be (corresponding author)

$\wedge^{\wedge}$ Rued Langgaards Vej 7, 2300 Copenhagen S, Denmark, +45 721850 00, malmborg@itu.dk; signelouise@itu.dk 


\title{
Scripting: an exploration of designing for participation over time with communities
}

\begin{abstract}
Designing participation over time is a challenge that is regularly discussed in the fields of Participatory Design (PD) and Codesign. This paper describes two living labs-cases concerned with designing IT during long-term engagements with communities. Both labs aim to enable participatory exchanges after the designer leaves and are thus confronted with challenges that transcend the time of the traditional design 'project'. We addressed these challenges via defining the IT design process as scripting, which is a process that better articulates the participants' different voices and timelines. In this process three types of scripts are made, supported by the facilitator role: personal scripts as portrayals of individuals' views on issues in the community and timelines to address these; community scripts aspiring to combine personal scripts into pluralistic views on the community and scripts for action as ways to rehearse how the community might unfold after the designer leaves. Key to this approach is that diverse people's views and timelines play a role in co-constructing IT platforms that support participation in the community over time. By creating IT tools that are enabled by and support scripting, designing for participation over time becomes a pluralistic endeavour.
\end{abstract}

Keywords: participatory design; codesign; scripting;

\section{The challenge of designing for participation over time}

In the fields of PD, Computer-Supported Cooperative Work (CSCW) and Codesign terms like 'use time' (Ehn 2008) or 'infrastructure time' (Karasti, et al. 2010) are used to discuss designing for participation over time after the designer leaves the project. They are meant to build bridges between the project's designers and the user. However, these two groups are not homogeneous. And yet, their wants and needs as well as their timelines for achieving them are often portrayed in a monolithic manner. Therefore, given the political background of these design fields for designing situations in which pluralistic voices can manifest themselves (Di Salvo, et al. 2012), the contribution of this article is to further develop the concept of scripting (as used in STS and by authors 
like Ehn and Sjögren 1992; Binder 1999; Storni 2013) as a design approach, which better articulates the diverse voices of actors and timelines within communities when designing for participation over time, independent from the design team. Our contribution is supported by two living lab cases that illustrate how the design of web platforms can be enabled by and support scripting.

Many design definitions do not account for a plurality of voices and timelines. Simon (1996), for instance, describes designing IT as the process of giving form to an inner environment (the entity of components out of which the artefact is built and their mutual relationships) and an outer environment (the external forces acting on the artefact and the interface between them). In this case, the role of a designer is to initially give 'form to an artefact,' which is then further impacted by the 'external forces' of an outer environment. In our view, the IT design process that aims to design participation over time, should not only be concerned with the designers' project and artefacts, but must also account for a diverse group of actors, projects and timelines.

We do not seek to propose yet another term for participation in the design process over time, as design, project, use or infrastructure time already cover this. Instead, we seek to investigate an alternative view on the design process that allows for a plurality of projects and timelines to come together. We explore this via the concept of scripting, which is used in the context of STS and specifies the design process as a group of human actors inscribing objects with their visions on the world, resulting in scripts that mediate action (Akrich 1992; Latour 2004). It is a process that supports giving both form and time to 'actions' made by a diversity of humans (and their future visions) and artefacts (that mediate in achieving these futures). It extends design's meaning beyond 'a designer' shaping an artefact for, or together with, 'a user', and pays attention to multiple human and non-human voices and timelines. 


\section{Scripting participation over time}

We specifically explore how the concept of scripting provides an alternative view on designing IT, which also supports participation over time. STS uses the term scripting in a descriptive study of human and non-human relations, for example present in buildings or information systems. We explore this idea in design, a field where scripting is used in a constructive and normative way. Here, a time aspect comes to the fore. Scripts describe, suggest or prescribe how a certain design will work in the future. For Storni (2013), there is a potential danger of 'colonising' scripts built upon the designers' perspective, who is highly influential in setting the timeline, goal or outcomes, that will in turn, normatively shape how the future evolves. Storni (Ibid.) sees the combination of describing both experts' as well as 'ordinary' users' scripts as a way to avoid this.

In PD and Codesign, the rationale of making 'ordinary people' both the subject and the starting point of scripts for the future has been explored via a series of approaches, including scenarios, storyboards or personas. However, these approaches often make abstract representations of 'real' people; reducing the plethora of voices to a controlled number of abstracted opinions. Additionally, they focus primarily on the users' current needs, and less so on creating space for imagining futures in which the studied subjects can actually participate. In contrast, design anthropological approaches in PD and Codesign have a tradition of focussing on how 'real' people deal with a certain issue as a starting point for future scripts (Blomberg and Karasti 2013). Design anthropology reacts against top-down approaches typical to many design processes, like urban planning processes that design for abstract groups of users (Clarke 2016). Mazé (2016) argues that design anthropology aids designers to go beyond singular notions of time as it allows for the expression of a plurality of experiences and expectations of time itself. Fieldwork is used to describe and reflect on multiple voices in everyday life 
and is translated in the constructive acts of giving form to the possible diverse futures and timelines to which these voices speak (Halse 2008). It reveals the politics of time, for instance how one voice (e.g. the designer) is given priority.

This tradition of working with 'real' people's interactions in everyday life to make scripts for the future, has been described by Ehn \& Sjögren (1992) and Binder (1999), who have explored 'scripts for action' as “a theatrical metaphor for collaborative exploration of new design possibilities among designers and users" (Binder, 1999, p. 230). Later these authors (Binder et al. 2011; Ehn, et al. 2014) show that when designing participation over time via living labs, the 'real' people are not only part of a theatrical stage in which they temporarily collaborate with designers in exploring and speculating about a future, but they also are partners in making their own stage. In this way, they can continue to collaborate among themselves, without the designers, to give form to their own community scripts for the future. Binder et al. (2015) see this process as democratic design experiments in which designers rehearse with diverse citizens how to organise themselves around issues with which they are concerned. It is "an active and delicate matter of proposing alternative possibilities just clearly enough to intrigue and prompt curiosity, and, on the other hand, to leave enough ambiguity and open-endedness to prompt the participants' desire to influence the particular articulation of the issue (Ibid., p 11)".

The aim of this article is to expand on this discussion of how scripting can provide an alternative perspective on designing participation over time that better articulates a multiplicity of actors, voices, and timelines. Based on the aforementioned literature, we identify three core design principles in scripting that will be further explored:

(1) the collection, through fieldwork, of the personal stories of participants, including 
how they deal with certain issues in daily life in the form of 'personal scripts' with their own timeline,

(2) the combination of these personal scripts in speculative 'community scripts' that deal with issues through working together to negotiate how timelines come together or conflict, and

(3) the rehearsal of each individual capability in making 'scripts for action' concerning how to self-organise in the making of both personal and community scripts for the future after the designer leaves her/his project.

\section{Scripting in the context of living labs}

We explored the ways in which scripting processes can take form through the examination of two cases in which web platforms were developed through a design process in order to enable participation within their respective communities over time. Both living labs are situated in dynamic design contexts which emphasise 'the potency on emergent everyday practice' (Binder et al. 2011, p. 7) in order to script new possibilities and action. Following Binder et al. (2011, p. 8) we perceived the work of the living labs as a 'process of transformation', where scripts for the future were rehearsed as new practices in close connection with everyday life. These scripts focused on sustaining participation after the design project came to an end. The authors designed the labs to be environments that would trigger people's interest in sharing their dreams about engaging with the community and working together to strengthening that community.

For the purposes of this paper, we interviewed key individuals (designer, policy makers, early enthusiasts, etc.) from each lab in order to examine the design processes of the respective lab's web platform. These interviews were used to highlight some of 
the turning points in the IT design processes related to the personal choices made by the individuals involved. Turning points are defined as holding a transitional quality (Graber and Brooks-Gunn, 1996) and thus aided in identifying which elements from a design project's timeline were consequential to individual participants and how these elements complement and diverge from each other in the scripting process (Huybrechts \& Hendriks, 2016). The resulting list of turning points revealed differing perspectives on which turning points mattered as well as the role of both IT and individuals in the realisation of these turning points, and the different timelines that were developed to fulfil these roles.

\section{Genk living lab}

Following a framework for European projects investing in economical and societal change through new PD approaches to urban public space, the authors developed De Andere Markt (DAM) lab in Genk, Belgium ( ${ }^{\circ}$ April 2015). The closure of local coal mines and a Ford automative plant (2014) in Genk, inspired the question that informed the materialisation of the lab namely, 'How can citizens, organisations, and the urban space itself play a role in shaping the future of work?' As a means of exploring this question further a web platform was developed in an iterative fashion in order to allow meaningful debate. This exchange was responsible for strengthening existing communities as well as fostering ones that would in turn shape the future of work.

The lab used a moveable DIY printing press that was mounted on a cargo bike to collect stories from locals in the public space. The printing press afforded locals the ability to make their own posters that explain their role in relation to changing working opportunities in the city. The scripting process thus began with the collection of personal stories through posters from local actors, including those who entered the living lab space as well as those the researchers encountered on the street. Researchers 
solicited these stories with the support of the neighbourhood managers, with strong ties to the community. These managers provided access to difficult to reach groups in the privacy of their home (e.g. Moroccan women). 150 stories were collected, photographed, filmed and edited to produce personal scripts. The scripts were displayed on the web platform and in the physical lab space located at street level (figure 1).

Figure 1. Web platform displaying personal scripts

To give an example of a personal script, during a June 2015 intervention we met a farmer, named Souliman. Souliman subscribed to a "land as king" philosophy and he shared with us his story of becoming a bio-farmer who started to grow herbs and vegetables on a small plot of land just outside Genk. "Now," Souliman told us, "My farm produces the equivalent of 76 bags of groceries". Souliman speculated on the development of a large piece of land situated inside the city. This oral account was rewritten to support a fluent reading experience and Souliman was portrayed realistically and at his best, and depicted holding a meaningful artefact (a basket, vegetables).

During the following months, Souliman and our team built relationships with several initiatives that focused on food inspired by Souliman's personal script. From this, a clerk of the town council advised us to talk to Berke, a 'compost master'. Soon thereafter we met Ilse, a cook who sought to invoke the power of preparing food to reach the most vulnerable in the community, participated in an event at the living lab that showcased the scripts of Souliman and others. The same exposure brought Ali, the owner of a Turkish shop, into the community as he expressed interest in selling Souliman's crops. Others too, like Lilli (the food service coordinator of a social employment organisation), and Wim and Katrien (growers of mushrooms) were either 
directly or indirectly inspired by Souliman's story. Some policymakers and researchers concerned with the redevelopment of an abandoned railway track in the city, saw his story and the network of other related stories as a great opportunity for developing a new type of economy centered around urban farming and slow food. Policymakers discovered that the railway track was in fact surrounded by green space, which at the time had been informally appropriated by farmers to grow crops or to keep animals. From a policy angle the focus turned to redeveloping the site into a park in which food could be grown, transported and sold.

To make the potential of the personal scripts for the community visible, from February 2016 until September 2017, a series of eight scripting workshops took place in the lab's physical shopfront. During these workshops designers, those who have created a script, and representatives from both the city and industry collaborated to transform the personal scripts (the individual stories as seen on the posters) into community scripts (how they work together). Workshop participants made the community scripts through clustering the personal scripts in different themes (food, energy, etc.) and then reflecting on how these scripts could work together. One theme that emerged was a community script about working together on the topic of food. In the scripting session, the participants speculated on how this theme could be translated into physical hubs "connecting a number of small and more large-scale food and nature initiatives in a cooperative, in the space where different landscapes intersect on the railway track". Byproducts of local farms and nature parks (e.g. organic waste) could be gathered and used to grow, prepare, and sell local food and dishes, which could then be transported via the track in order to be sold in neighbourhood shops and restaurants. During this development process of the hubs and the cooperative, the web platform was further developed to communicate the community scripts in relation to its spatial context and to 
personal scripts as well. The spatial clustering of the scripts on an online map (figure 2) supported the further development of individual's personal scripts in relation to each other and to their role in the city space. The first prototypes of the web platform clustered personal scripts in both a thematic view and a spatial view. These prototypes allowed people to discover interesting links between their activities, the connections between the different personal and community scripts as well as the individual and project timelines on food and other themes.

Figure 2. Web platform displaying the scripts in a spatial view

The third phase was then concerned with taking the community scripts and translating them into scripts for action. In September 2016 and then again one year later, a group of 15 local actors in the 'food' group built prototypes of the physical hubs together with a group of architectural researchers. One prototype was a micro house in a community garden, where a gardener could process her vegetables in a kitchen and which could then act as a market stall that faced the railway track, where the product could then be sold. The intention was to install such a micro house in all 70 community gardens alongside the track. By building this house, the group started 'acting' as a cooperative and began sharing concerns ("How do we work hygienically?") as well as techniques (“How can we quickly cool freshly prepared food?”). By making goals, concerns and plans explicit, the community script on the cooperative became tangible for the larger group of participants. This led to conflict as one community gardener felt that the script was overly dominated by the personal scripts of a handful of gardeners. The script was opened again for a larger diversity of approximately 70 community gardeners. After some weeks, the group appointed a more 'neutral' facilitator - a city administrator - to start negotiations with the city to realise some scripts, such as the start-up of the 
cooperative. The city administrators, members of civil society and key community members continuously provided input on how the web platform could support the process of facilitating negotiations and mitigating conflicts between personal scripts over time. This led to the realisation that the web platform needed to provide more explicit roles to city administrators as facilitators. It also became clear that there was a need for a 'time view' on top of the thematic and spatial views. This would provide more insight into how the diverse time-expectations of the personal scripts (e.g. the construction of one micro house versus preparing a piece of farmland) could be planned for in relation to each other, over time, and how they fit within the greater community scripts (e.g. the creation of the cooperative). It is the intention of this project that by December of 2018 the web platform will functionally support collective collaboration in the creating and sharing of personal and community scripts and scripts for action.

\section{Frederiksberg living lab}

Following a framework for European projects aimed at codesigning digital sharing services amongst senior citizens involved in communities (e.g. IT-volunteers from the library, or a walking group) the Give\&Take project ( ${ }^{\circ}$ May 2014) was developed in Vienna, Austria and Frederiksberg, Denmark. This paper reports on the work done on the Danish project. Give\&Take designed a platform that allowed to exchange services and resources among senior citizens in a reciprocal fashion. Unlike many existing social media platforms, this platform was designed to support existing, often loosely coupled communities in order to strengthen and sustain these communities, while simultaneously acknowledging privacy and accessibility concerns for users with low level of computer literacy.

During the first year, the project group engaged 9 senior communities to discuss what sharing meant to them and how sharing could be explored in the future. First, the 
researchers met with senior citizens of the individual communities. Later, all 9 communities were gathered for a series comprised of four codesign workshops. At these initial meetings, dialogues with the seniors were facilitated via codesign games to gain insight into what sorts of things were shared and how individuals shared these items as well as what their concrete timelines in sharing were (e.g. weekly walks). The participants were encouraged to create game board-collages (figure 3) that visualised the bringing-together of participant voices in a variety of personal scripts.

Figure 3. A game board-collage of personal scripts

The various personal scripts were used as a starting point for imagining possible futures for sharing in these communities, and how a digital platform could in fact support such futures. This resulted in community scripts that were enacted by the participants through doll-playing and performances (figure 4). The community scripts were the foundation for an organisational structure of an online sharing platform, based on 'the onion model' where different roles or levels were defined (sharers, volunteers, coordinators) and a high level of emphasis was placed on the connection with an institution (a municipality). Potential coordinators were social workers, health counsellors from public health centres and others who work closely with senior communities. This structure of the platform allowed for sharers, volunteers (as part of the communities) and the coordinators to all be present on the platform, with varying levels of access. It gave the coordinators the possibility to facilitate the groups and provide 'a helping hand' from a distance. This facilitator role was further developed in a co-design workshop with potential coordinators.

Figure 4. Enacting of community scripts that led to the 'onion model' of roles. 
The personal scripts expressed the desire for members to know each other in advance, accepting only members who they had already met in physical life. Therefore, the final design was a sharing platform structured around existing - though loosely coupled or more vulnerable - communities. The presence on the platform was always as a member of a community and not just a personal profile-page, as Facebook for instance.

To translate the community scripts that emerged during the workshops into scripts for action, the project group established five living labs over the course of the last 18 months. The platform was brought into the everyday life of different senior communities. The goal was to rehearse the role of the platform in how sharing could potentially take place and to discover how the platform could be sustained in these communities after the project.

A walking group for senior citizens initiated by a health counsellor was one of the living lab groups established. It consisted of 10-12 senior citizens who met every Monday to walk together for an hour and drink coffee afterwards. The health counsellor recruited the majority of participants among those who recently lost their spouse. The researchers took part in the Monday walks for six months in order to explore the platform together with the seniors and the health counsellor. The platform slowly turned into a place where stories and issues from everyday life could be shared: from stories of how their spouse passed away to pictures of their grandchildren. Walking group participants also began to use the platform to plan meet-ups at local events. To rehearse how best to connect the walking group with the health counsellor, the researchers (based on a suggestion from the counsellor) arranged that the walking group shared their weekly trip (figure 5) along with information on how many showed up, weather conditions and special incidents. The health counsellor could then remotely get an 
impression of the community's well-being and reach out in a 'helping hand' capacity when necessary. One of the women was unable walk the same distance as the others. This was a concern, since the group liked the long walks but did not want to leave this woman behind. After some discussion, the walking group asked the counsellor for help through the platform. The health counsellor followed up on this by recruiting new members in the same 'physical condition', so that the woman would not feel left alone.

Figure 5. Screenshot from the walking community with latest walk (from Endomondo).

Through the first round of living labs, it became obvious that the coordinators needed time and support with the introduction and adoption a new digital (facilitation) practice. In an attempt to script a possible service package around the platform and then in turn translate this into scripts for action, researchers rehearsed the facilitator role together with social workers and health counsellors. Through using the platform (including a special dashboard view for coordinators), they were able to see new possibilities as to how the platform could support their work. One health counsellor, for instance, recognized the opportunity to make a former initiative, a (single) men's cooking club, self-sustaining. She re-initiated the cooking club and the researchers supported her in using the platform to explore whether or not the club could become self-sustaining and how this could in fact be achieved.

These living lab stories on how the communities and the coordinators developed their practices at their own pace through the use of the platform were used to script the content of the service package. One of the outcomes of the project were these examples of practices. 


\section{Discussion: scripting participation over time}

We will critically discuss how the three specific 'products' of the scripting process (personal, community scripts and scripts for action) closely interact with the facilitator role as a catalyst that enables community participation over time as well as the intersection of this process with that of IT development.

\section{Describing personal scripts}

In a first scripting process, the design researchers (as facilitators) created web platforms to support displaying personal scripts of community members with the aim of highlighting how these actors can influence the community in the future. These websites communicated personal scripts that increased exposure, identification, and imagination of a possible future for other community members reading such scripts. These stories are about real actors with names, narratives, and desires who do not only function as inspiration for the design requirements of an IT platform, but intrinsically became a part of the platform. By portraying the individual narratives carefully via different media, the personal scripts act as a 'catalyst' for members of the communities to relate to. As the walking group already shared the common theme of walking, the personal scripts shared via the platform stimulated non-thematic and off-topic interactions and attracted new members to join. Community members came together based on shared interests or because they felt as if they know the other person better thanks to the sharing of personal information. DAM-communities used the scripting process and the platform to gather around shared themes and discovered shared issues and solutions in dealing with food in the city.

Scripting thus takes a different stance on how people are represented in the IT design process. Personas, and similar methods, have proven to be a help in the design of IT. However, they risk to present a reductive view on people's uniqueness through 
keeping a safe distance (Portigal 2008). The designer then 'colonises' the users' different scripts and timelines by 'moulding' them into one monolithic script, following one selected timeline. In PD and Codesign, as exhibited by the described cases, the script researchers produce with participants is often politically grounded and focused on richness and plurality. People participate as 'themselves', instead of as a 'representative for a particular community'. Self-evidently, this raises different types of ethical questions surrounding the research subjects also being those represented in the IT design. While some may be interested in giving input, they might not wish to be represented online. This process thus requires careful work with continuous questions resulting in consent and feedback loops. To allow for this, the scripts were discussed during Codesign encounters between designers and community members. The combination of having a repeated representation of scripts on a digital platform as well as in physical meeting points (shopfront or workshop space) enabled a continuous negotiation and discussion of the interests of the persons represented in the scripts. Returning to our earlier discussion on personas, these continuous negotiations with community members ensure consent while avoiding the colonising of the users' scripts and timelines through 'moulding' them into one script for one persona. Through shared scripting over time, we can make room for the plurality of voices in a common space of negotiation.

\section{Speculative gatherings into community scripts}

In a second scripting process the IT tools employed supported the design researchers to further speculate with the community about what people - represented in the personal scripts - can do together with their (potential) communities. This results in community scripts that are shared and discussed. The personal scripts on food, for example, triggered the creation of a community script on a food cooperative. In the first stages of 
both living labs the community scripts were created with the design researchers in a physical space during physical workshops, in order to rehearse the activity of making community scripts on a web platform.

It became clear in the cases that representation should be carefully handled in the making of community scripts. The script is always led by a particular group of people in which some people are included and others excluded and in that way, can give rise to conflicts. Therefore, offering time to speculate on these scripts before taking steps towards realising them plays an important role in providing room for a multiplicity of voices in these conflicts.

\section{Scripts for actions over time}

To allow for the self-organisation of the scripting processes of personal and community scripts by diverse community members with different visions and timelines, the design researchers in the living labs paid close attention to the role of time in the process.

Scripting was seen as a design activity that gave form to pluralistic actions over time, as opposed to focusing on artefacts alone. Time is not represented as a singular path defined by the designer, but as multiple paths defined differently in individual timelines.

The two labs experimented with IT tools to collaboratively plan such a plurality of participatory actions over time. This allowed for further development of the activating role of IT tools as a means for people to openly coordinate actions to develop these multiple pathways and timelines. To make this possible in the context of the two living labs, IT was not only inspired by the research and the research subjects, but it was developed in parallel with the self-organisation of the community being studied. The platforms were designed to support the rich diversity of 'research subjects' to document their everyday ways of dealing with issues, shape their vision on possible exchanges in a community in the future, and ultimately provide an afterlife for them. These web 
platforms heralded and activated individuals by offering a particular space to the uniqueness of a personal script. Through further development, the web platforms can function as a catalyst for a particular community script. In this paper, we identified two different ways of how this was approached. In the first type, personal scripts of people in existing communities, (e.g. walking community) were represented and shared, so that members could identify with them in order to strengthen their existing community. In the second type, personal scripts linked to a specific location or theme (e.g. Souliman) were represented as a point of identification for others to form new communities (e.g. on food).

\section{Scripting to support transfer of the facilitator role}

The participatory planning of the scripts (e.g. setting up a cooperative) was not selfevident to community members. Because of this, rehearsing in the living labs during the scripting process, was crucial in allowing community members to strengthen their capabilities in taking part in the organisation of community life. Both labs quickly realised that this self-organisation could not only partly take place by citizens alone. Therefore, a facilitating role was not only needed during the design process of the web platforms, but also afterwards to support participation over time and to clarify responsibilities of all members. We suggested scripting as a way to provide room for, while simultaneously facilitating, a multiplicity of voices. As Binder et al (2015, p. 10) suggest, this facilitation process is not a passionless exercise in which 'everyone' is allowed to voice an opinion. In both cases, this process was rather a continuous rehearsal of the web platforms' potential for supporting self-sustaining negotiations in pluralistic communities with limited need for facilitation. While known social media, such as Facebook, Twitter or Instagram, mainly focus on presenting personal scripts, the Give\&Take and DAM-web platforms are experiments on strengthening existing, and 
growing new communities, via arranging personal scripts in relation to each other in order to give form to different types of community scripts and scripts for action.

The DAM-web platform is an experiment in the ways in which data can be visualised in such a manner that it acquires a facilitating role. The web platform also needs to provide room for an explicit facilitator, in this case a design researcher and a city administrator, to moderate between different groups when they make the move from community scripts towards planning their actions over time.

The Give\&Take-web platform provides a new approach for municipalities and care-giving organisations to establish sustainable relations with senior citizens and volunteers through the health counsellors' role as facilitators. Based on community scripts from the workshops, this platform was equipped with a facilitator role ('helping hand') that was carried out by health counsellors. Over the course of our research, it became clear that the Give\&Take-web platform would be a platform specifically for (more vulnerable) groups of seniors that needed some support from a facilitator.

The following overview in figure 6 summarises how the facilitator role supports the scripting process of personal, community scripts and scripts for action.

Figure 6. Overview of the scripting process

\section{Conclusions: the facilitator role in designing participation over time}

This paper further developed the concept of scripting by Binder et al (2015) as a design approach that facilitates a pluralistic set of voices, through the development of IT products. We specifically explored a challenge Binder et al. touched, but did not elaborate upon; namely how the concept of scripting can support designing participation over time. The outcome of our discussion was that scripting participation over time, is not only about setting up a facilitation process that nurtures pluralistic views on an issue 
in a community (which has been framed as democratic design experiments by Binder et al, 2015), but it is also about experimenting with how to pass on this facilitation role, over time, once the designers are no longer involved with these communities. Since this became a core concern in both cases and we believe this can be a challenge for future researchers, we conclude this article with summarising three ways in which passing on the facilitation role to the communities was approached.

A first approach was the setup of living labs, in the line of work of Binder (2011) and Ehn et al. (2014). These were conceived as places, where a varying array of community member views on issues and community roles could be unfolded in parallel with the development of the web platforms.

A second approach was to develop web platforms with members of the local community in order to support them in (1) expressing their personal scripts in relation to issues in their environment, while providing room for their individual time-expectations regarding the achievement of specific goals in relation to these scripts, (2) creating community scripts members want to develop together with others, that also reflect their own time-related character, (3) making scripts for action in order to rehearse with community members how to use the web platforms to coordinate actions in the community and through doing so to participate in the codesigning of the IT being used.

A third approach was the clarification and rehearsal of roles. To motivate people to not only create scripts about their role in their respective communities (such as setting up a food cooperative), but to also perform these roles meaningfully, requires many (physical) encounters. These encounters allowed for the rehearsal of these roles over time as a means of dealing with the inevitable conflicts inherent to self-organising communities. This rehearsal also occurred when the local facilitators (often with an institutional connection) were introduced. The facilitators could actively involve - 
especially vulnerable - groups in the local context through discussions that took place both in the living labs and online. In the end, this facilitator role turned out to be essential. The cities have limited resources for social initiatives, and are therefore tempted to avoid the facilitation. Our scripting for action demonstrated in both cases, that the facilitator role was crucial for designing inclusive initiatives and allowing (vulnerable) citizens to not only participate but to stay on board as well.

To summarise, this paper has contributed to the existing discourse on scripting by providing insight on how time is a concern in the facilitation process of pluralistic voices within communities. Defining the design process as a scripting process in which each community member produces a script for her or his own projects within the community, moves away from design from one temporal perspective namely that of the designer working towards her/his IT product deliverables to that in which the various interpretations of time that exist within a community are taken into account. Scripting sets the stage for designers to facilitate a process within a community in which diverse community members can articulate their own projects and timelines and, also, to transfer this facilitation role. To allow for this pluralistic understanding of participation over time, the scripting processes in the two cases explored here, intensely intertwined the rehearsals of expressing personal, community scripts and scripts for action with that of the design of IT platforms and the clarification of roles within these scripts.

Conceptualising design as scripting, liberates us from the time restrictions of a design process: that of the designer or the user. When designing IT tools that are enabled by and support scripting, designing for participation over time becomes a pluralistic endeavor. 


\section{References}

Akrich, Madeleine. 1992. “The de-Scription of Technical Objects.” In Shaping

Technology/Building Society, Wiebe Bijker and John Law (eds.), 205-24. Cambridge, MA, US: MIT Press.

Binder, Thomas. 1999. "Setting the Stage for Improvised Video Scenarios.” In CHI '99 Extended Abstracts on Human Factors in Computing Systems, 230-231. CHI EA '99.

New York, USA: ACM. doi:10.1145/632716.632859.

Binder, Thomas, Eva Brandt, Pelle Ehn, and Joachim Halse. 2015. “Democratic Design Experiments: Between Parliament and Laboratory." CoDesign 11 (3-4): 152-65. doi:10.1080/15710882.2015.1081248.

Binder, Thomas, Eva Brandt, Joachim Halse, Maria Foverskov, Sissel Olander, and Signe Yndigegn. 2011. "Living the (Codesign) Lab.” Nordic Design Research Conference, $1-10$.

Blomberg, Jeanette, and Helena Karasti. 2013. "Reflections on 25 Years of Ethnography in CSCW." CSCW 22 (4-6): 373-423. doi:10.1007/s10606-012-9183-1. Clarke, Rachel. 2016. “The New Design Ethnographers 1968-1974: Towards a Critical Historiography of Design Anthropology.” In Design Anthropological Futures., Rachel Charlotte Smith, K T Vangkilde, M. G. Kjaersgaard, Ton Otto, Joachim Halse, and Thomas Binder (eds.). New York: Bloomsbury.

Di Salvo, Carlo, Andrew Clement, and Volker Pipek. 2012. "Participatory Design For, With, and By Communities.” In International Handbook of Participatory Design, Jesper Simonsen \& Toni Robertson (eds.), 182-209. Oxford: Routledge. Ehn, Pelle. 2008. "Participation in Design Things." In Proceedings of the Tenth Anniversary Conference on Participatory Design 2008, 92-101. PDC '08. Indianapolis, USA: Indiana University. http://dl.acm.org/citation.cfm?id=1795234.1795248.

Ehn, Pelle, Elisabet M Nilsson, and Richard Topgaard. 2014. Making Futures: 
Marginal Notes on Innovation, Design, and Democracy. MIT Press.

Ehn, Pelle, and Dan Sjögren. 1992. "From System Descriptions to Scripts for Action."

In Design at Work, Joan Greenbaum and Morten Kyng (eds.), 241-268. Hillsdale, NJ,

USA: L. Erlbaum Associates Inc. http://dl.acm.org/citation.cfm?id=125470.115550.

Graber, Julia A., and Jeanne Brooks-Gunn. 1996. "Transitions and Turning Points:

Navigating the Passage from Childhood through Adolescence.” Developmental

Psychology 32 (4): 768.

Halse, Joachim. 2008. "Design Anthropology: Borderland Experiments with

Participation.” Copenhagen, Denmark: ITUniversity Copenhagen.

http://nordicom.statsbiblioteket.dk/ncom/services/downloadRegister/86421/design_anth ropology-1.pdf.

Huybrechts, Liesbeth \& Hendriks, Niels. 2016. "Counterfactual scripting: acknowledging the past as a resource for PD". Proceedings of the 14th PD Conference: Full Papers - Volume 1: 111-120.

Karasti, Helena, Karen S. Baker, and Florence Millerand. 2010. “Infrastructure Time:

Long-Term Matters in Collaborative Development." CSCW 19 (3-4): 377-415. doi:10.1007/s10606-010-9113-z.

Latour, Bruno. 2004. Politics of Nature. Harvard University Press.

Mazé, Ramia. 2016. "Design and the Future: Temporal Politics of 'Making a

Difference."' In Design Anthropological Futures., Rachel Charlotte Smith, K T

Vangkilde, M. G. Kjaersgaard, Ton Otto, Joachim Halse, and Thomas Binder (eds.).

New York: Bloomsbury.

Portigal, Steve. 2008. "Persona Non Grata." INTERACTIONS-NEW YORK- 15 (1): 72.

Simon, Herbert A. 1996. The Sciences of the Artificial. MIT press.

Storni, Cristiano. 2013. "Design for Future Uses: Pluralism, Fetishism and Ignorance." Nordes $1(5)$. 
